\title{
ANÁLISE DO CIPROFLOXACINO EM AMOSTRAS DE MEDICAMENTOS DE REFERÊNCIA, SIMILAR E GENÉRICO POR ESPECTROSCOPIA NO INFRAVERMELHO
}

\section{Caroline Aparecida Lima ${ }^{1}$ \\ Rafael Viana Toledo ${ }^{2}$ \\ Kumiko Koibuchi Sakane ${ }^{3}$}

Resumo: O ciprofloxacino é um antibiótico ativo contra bactérias gram negativas e indicado para infecções do trato urinário, prostatites, gastroenterites severas, doenças sexualmente transmissivéis (DSTS), infecções da pele e tecidos moles, não indicado em Pneumonias por S. pneumoniae. O presente trabalho analisou qualitativamente, por espectroscopia no infravermelho, amostras de medicamentos de referência, similar e genérico que contenham o princípio ativo ciprofloxacino. Nas amostras avaliadas foram verificadas que a espectroscopia no infravermelho é viável mesmo para amostras com uma concentração pequena de princípio ativo e que os espectros das três amostras seguem os padrões exigidos pela ANVISA.

Palavras-chave: Ciprofloxacino; Espectroscopia no Infravermelho; Antibiótico; Antimicrobiano.

\footnotetext{
${ }^{1}$ Mestrado em Bioengenharia/Univap, Brasil. E-mail: caroladelima@outlook.com.br.

${ }^{2}$ Mestrado em Bioengenharia/Univap, Brasil. E-mail: rafaeltoledo4@hotmail.com.

${ }^{3}$ Universidade do Vale do Paraíba/Univap, Brasil. E-mail: kumiko@univap.br.
} 